\title{
Innovative matrix for applying a food systems approach for developing interventions to address nutrient deficiencies in indigenous communities in India: a study protocol
}

\author{
Suparna Ghosh-Jerath ${ }^{*}$ (D), Shauna Downs ${ }^{2}$, Archna Singh ${ }^{3}$, Santanu Paramanik ${ }^{4}$, Gail Goldberg ${ }^{5}$ and Jessica Fanzo ${ }^{6}$
}

\begin{abstract}
Background: Indigenous communities retain knowledge of the land and food resources rooted in historical continuity within their region of residence. Food systems research can be leveraged to identify strategies to encourage sustainable use of complex multi-species agroforestry systems by indigenous communities contributing to nutritional needs while simultaneously preserving the ecosystems and their benefits to society. Till date, the analyses of food systems have predominantly focused on high income countries often overlooking the alternatives (dietary and production) that would be most relevant to low and middle income countries (LMIC). Thus, innovative methodological approaches are needed to comprehensively characterize diverse food systems in LMICs with special reference to indigenous communities.

Design: This protocol paper describes a food systems approach that will be employed to understand diverse and dynamic food systems of vulnerable tribal communities of Jharkhand, India and leverage their agroforestry systems to improve dietary diversity, nutrition status and address food security. Four tribal groups namely Santhal, Ho, Munda and Sauria Paharia of Godda, West Singhbhum and Khunti districts of Jharkhand would be studied.

This will be an exploratory cross-sectional study design, along with a longitudinal component to capture seasonality in dietary intake and agricultural diversity. A mixed methods approach will be used based on a conceptual framework on drivers of food systems, food supply chain, food environment (both wild \& cultivated, and market food environments), as well as consumer behaviour and maternal and child health outcomes in tribal communities. The quantitative surveys will be conducted on socio-economic, demographic profile of households, their availability of, access to and utilization of food environment and nutritional status of reproductive age group women and children under 5 years. Qualitative enquiries will examine barriers and facilitators to increase sustainable production, procurement and consumption of indigenous foods. The final outcome would be development of interventions to promote indigenous food consumption.
\end{abstract}

Discussion: By utilizing a combination of value chain analysis and 'Optifoods linear programming software' that will use above information on indigenous community, dietary intake, nutritional status and food environment, evidence based interventions promoting indigenous food systems aimed at addressing food and nutritional security of tribal communities will be developed.

Keywords: Food systems research, Indigenous foods, Indigenous communities, Nutritional deficiencies

\footnotetext{
* Correspondence: suparna.ghoshj@iiphd.org

'Indian Institute of Public Health-Delhi, Public Health Foundation of India,

Plot no 47, Sector 44, Institutional Area, Gurgaon 122002, India

Full list of author information is available at the end of the article
}

(c) The Author(s). 2019 Open Access This article is distributed under the terms of the Creative Commons Attribution 4.0 International License (http://creativecommons.org/licenses/by/4.0/), which permits unrestricted use, distribution, and reproduction in any medium, provided you give appropriate credit to the original author(s) and the source, provide a link to the Creative Commons license, and indicate if changes were made. The Creative Commons Public Domain Dedication waiver (http://creativecommons.org/publicdomain/zero/1.0/) applies to the data made available in this article, unless otherwise stated. 


\section{Background}

The central paradigm of survival is the maintenance of the integral synergism between humans and their environment. While modern agricultural practices to improve food sufficiency have increased agricultural productivity, they have also put a strain on the environment. Food production (and the way it moves along the value chain) that primarily focuses on mono-cropping makes diets less diverse, alongside contributing to biodiversity loss and environmental degradation. As such it is associated with large carbon and water footprints making our current food system unsustainable [1-3] Despite an increase in the productivity of major food crops, the number of people around the world who are food and nutrition insecure remains high, with many countries battling with multiple burdens of malnutrition. On one hand, 821 million people are undernourished, over 50 million children under five are wasted and 770 million people have severe food insecurity. Further, 151 million children under five years of age are stunted and approximately two billion people worldwide have micronutrient deficiencies. Coinciding with the burden of undernutrition, is the increasing prevalence of overweight and obesity as well as diet-related non-communicable diseases (e.g., diabetes, cardiovascular disease, etc.) [4-6]

Most of the world's food insecure people live and work in rural areas - small-scale subsistence farmers still constitute $50 \%$ of rural populations in developing countries [7-9]. Indigenous and tribal people who rely on subsistence farming, are descents from populations, who inhabited the country or geographical region at the time of conquest, colonisation or establishment of present state boundaries and have their own cultures, languages, customs and institutions. In addition to that and importantly, they retain knowledge of the land and food resources rooted in historical continuity within their region of residence. [10, 11].

Nevertheless, many subsistence crop production systems of these indigenous communities are characterized by low productivity and instability of production often attributed to marginal and erratic rainfall. $[12,13]$. However, globally we also have scenarios where indigenous knowledge has enabled the communities to enhance subsistence farming at the time of seasonal and climatic variability. This is often referred in literature as 'community based adaptation' defined as community led processes based on community's priorities, needs, knowledge and capacities which have empowered people to plan and cope with the impacts of climate change $[4,14,15]$.

Food systems research can be leveraged to help understand and explore these indigenous food systems and analyse the gaps in food production and challenges that hinder access and optimum utilization by these vulnerable indigenous populations. More specifically, strategies can be identified that can encourage the sustainable use of complex multi-species agroforestry systems (AFS) (see Table 1) by these indigenous communities that can contribute to meeting nutritional needs while simultaneously preserving the ecosystems and its benefits to society $[19,20]$.

Despite the traditional ecological knowledge (TEK) and availability of rich AFS, indigenous communities are often vulnerable to nutritional deficiencies and food insecurity [21]. Since AFS biodiversity does not necessarily translate into dietary diversity and food security of these communities, ways are needed to leverage the potential of AFS by contextualizing associations among agricultural diversity that exists within subsistence farming systems, dietary diversity, nutritional status and food security [22].

Thus, to improve sustainability and support a healthier and nutritious food supply in vulnerable indigenous communities, [7, 23] suitable frameworks for identifying strategies to promote utilization of indigenous food resources are required. Till date, the analyses of sustainable diets and food systems have predominantly focused on high income countries often overlooking the alternatives (dietary and production) that would be most relevant to LMICs. Thus, innovative methodological approaches are needed to comprehensively characterize diverse food systems in LMICs with special reference to indigenous communities. [24].

The food system encompasses the elements and activities that relate to the way in which food is produced, processed, distributed, prepared and consumed, and the outcomes of those activities in terms of nutrition, health, equity and the environment [25]. In order to ensure that populations worldwide have access to culturally appropriate food that meets their nutritional needs, food systems need to be leveraged in order to improve the quality of food that is produced, moves along the food supply chain, and is available, affordable, safe and desirable within food environments. By applying a food systems approach for examining the nutritional challenges faced by indigenous populations in LMICs, there is greater potential to identify upstream drivers of food choice and potential solutions

Table 1 An overview of Agroforestry Systems (AFS)

\begin{tabular}{ll}
\hline Definition & AFS combines wild and domesticated plants, \\
& animals, fungal and micro-organic components as \\
& well as their interactions. It also includes trad- \\
itional species of foraged and cultivated floras and \\
faunas that are adapted to the local geographical, \\
climatic and growth conditions [16]. \\
AFSs are designed and managed based on \\
mignificance \\
world and are expressions of their traditional \\
ecological knowledge and biocultural heritage \\
[17, 18], of which indigenous communities are \\
important custodians [9]. \\
The usage of AFs by indigenous communities \\
make it a potentially important strategy for \\
intervention \\
providing low resource intensive, nutrient rich \\
and sustainable sustenance [7].
\end{tabular}


across sectors to confront the challenges of improving nutrition and health, while simultaneously protecting the environment [24]. Further, it is important to document the spectrum of ecosystem management, roles of agroforestry, TEK and human culture for food sovereignty in LMIC set up through a defined approach [26].

Our present study, will employ a food systems approach to understand the diverse and dynamic food systems of vulnerable tribal communities of Jharkhand, India and leverage their AFS to improve dietary diversity, nutrition status and address food security. This will allow us to gain a thorough understanding of the food system as a whole, the multiple synergistic factors and drivers of food choices and to identify points of intervention throughout the food system to support good nutrition among these vulnerable communities. This will culminate in the development of an innovative matrix to analyze indigenous food systems in the LMIC context.

\section{Methods/design}

\section{Study setting and population}

Despite bountiful natural resources, Jharkhand, a state in the central eastern part of India is amongst the poor performing states with one of the highest burdens of malnutrition. The state has a large indigenous population (26.2\%), known as the Scheduled Tribes (ST) with a total population of the state being 32 million [27]. Out of thirty of such Scheduled Tribes in the State, the Santhal are the most populous constituting $34 \%$ of the state's total indigenous population. The Oraon (19.6\%), Munda (14.8\%) and Ho (10.5\%) tribes also make up a large proportion of the total ST population of the State. Sauria Paharias (less than 1\%) are one of the primitive tribal groups in Jharkhand (and are considered as particularly vulnerable) [27]. Our study will focus on the Santhals, Ho and Munda tribes of Jharkhand as well as the Sauria Pahariya tribes given their vulnerability. The study districts would include Godda, West Singbhum and Khunti as they have high concentration of the specific tribal groups under study.

\section{Overview of conceptual framework}

Figure 1 depicts our project's conceptual framework, which describes the drivers of the food system, the food supply chain, the food environment (both wild and cultivated, and market food environments), as well as consumer behaviour and maternal and child health outcomes in tribal communities in Jharkhand. We adapted the conceptual framework of the food systems from the High Level Panel of Experts (HLPE) report on Nutrition and Food Systems, [25] to develop our framework to better reflect our study population and design.

The drivers of food systems in tribal communities in Jharkhand feed into the food supply chain and food environments which then influence the availability, diversity, desirability, safety and affordability of foods. These factors, along with consumer preferences, affect the foods that these communities acquire and consume. The

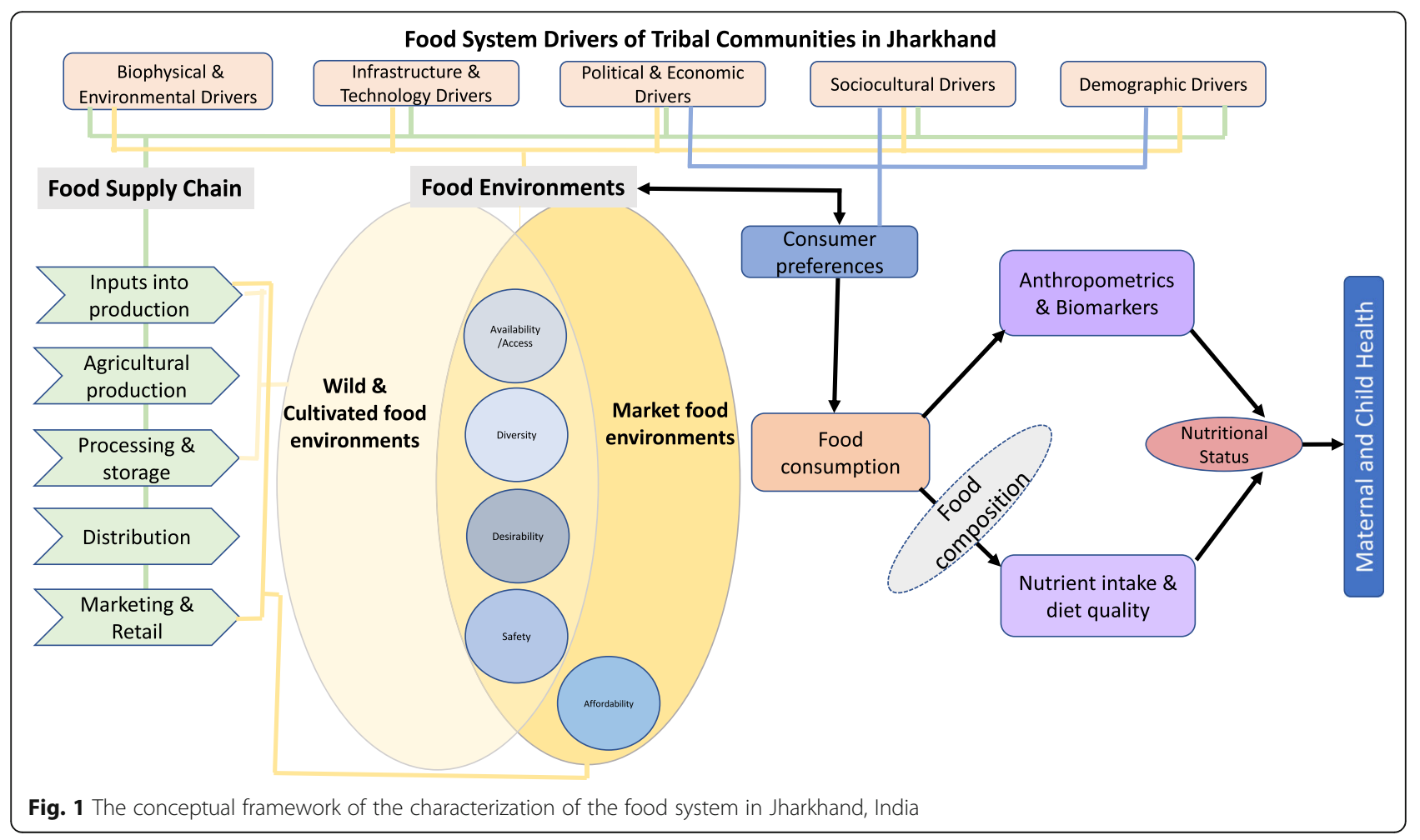


nutrient composition of consumed foods has significant implications in terms of nutrient intakes and diet quality, body composition and micronutrient status, thus influencing nutritional status and maternal and child health outcomes.

\section{Aim of the study}

The overarching aim of this study is to evaluate the potential of indigenous foods in contributing to dietary diversity and nutrient intake for improving food security and nutritional status of vulnerable tribal communities of Jharkhand, India. The specific objectives of this study, target four main areas: 1) characterizing the food environment; 2) assessing the nutritive value of indigenous foods that are routinely accessed; 3 ) estimating the contribution of indigenous foods to nutrient intake and nutritional status of the communities; and 4) informing the development of interventions to support indigenous food consumption.

\section{Overarching study design}

We will use an exploratory cross-sectional study design, along with a longitudinal component to capture seasonality, in order to examine the food system of tribal communities in Jharkhand.

\section{Study procedures}

A mixed methods approach will be used for addressing each of the four objectives of the study.
Figure 2 provides an overview of the different methods that will be used as part of this study and for assessing different components of the conceptual framework addressing each objective of the study. We describe these methods in additional detail below.

\section{Overall sample}

A two-stage cluster sampling design will be adopted for each of the tribal groups. Although there are some variations in the sampling strategy across tribal groups, the general methodology consists of first randomly selecting villages (from purposively chosen blocks based on the population density of tribal groups under investigation) using probability proportional to size (PPS) sampling, with size being the number of households in the village as per census 2011. Villages with less than 50 households will be excluded, as the required number of eligible households (having at least one child 6-59 months of age) may not be available. In the second stage, a house-listing exercise will be carried out in all sampled villages in order to construct the sampling frame of eligible households, as described in additional detail below. Under the assumption of needing at least 20 eligible households per village, we plan to select 14 villages (from purposively chosen blocks; a block is defined as an administrative sub division of a district) for each of the four tribal groups; Santhal, Ho, Munda and Sauria Paharia. For each tribe, the total number of villages $(n=$ 14) will be distributed approximately equally to selected

\begin{tabular}{|c|c|c|c|c|c|c|c|c|c|c|c|c|c|c|c|c|c|}
\hline \multirow[t]{2}{*}{ Study Methods } & \multicolumn{3}{|c|}{ Food System Drivers } & \multicolumn{5}{|c|}{ Food Supply Chain } & \multicolumn{4}{|c|}{ Food Environments } & \multirow[b]{2}{*}{ 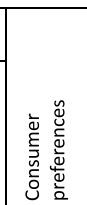 } & \multirow[b]{2}{*}{ 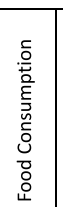 } & \multirow[b]{2}{*}{ 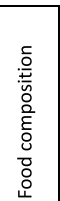 } & \multirow[b]{2}{*}{ 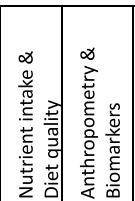 } & \multirow[b]{2}{*}{ 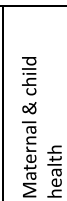 } \\
\hline & 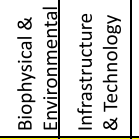 & 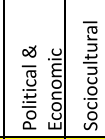 & 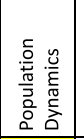 & 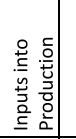 & 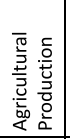 & 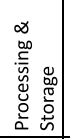 & 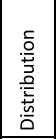 & 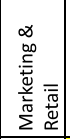 & 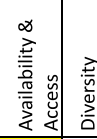 & 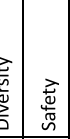 & 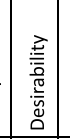 & 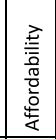 & & & & & \\
\hline \multicolumn{18}{|l|}{ Village transect } \\
\hline \multicolumn{18}{|c|}{$\begin{array}{l}\text { FGD (including free listing \& pair } \\
\text { wise ranking) Indigenous foods }\end{array}$} \\
\hline \multicolumn{18}{|c|}{$\begin{array}{l}\begin{array}{l}\text { FGD on climate change and } \\
\text { resilience }\end{array} \\
\end{array}$} \\
\hline \multicolumn{18}{|c|}{$\begin{array}{l}\text { FGD on facilitators and barriers } \\
\text { to indigenous food production } \\
\text { and consumption }\end{array}$} \\
\hline \multicolumn{18}{|l|}{ Household survey } \\
\hline \multicolumn{18}{|l|}{$24 \mathrm{hr}$ recall/FFQ } \\
\hline \multicolumn{18}{|c|}{\begin{tabular}{|l} 
Anthropometry + biomarkers \\
\end{tabular}} \\
\hline \multicolumn{18}{|l|}{\begin{tabular}{|l|} 
Value chain analysis \\
\end{tabular}} \\
\hline \multicolumn{18}{|l|}{ Market surveys } \\
\hline \multicolumn{18}{|l|}{\begin{tabular}{|l|l} 
Agricultural diversity tool \\
\end{tabular}} \\
\hline \multicolumn{18}{|l|}{ Nutrient analysis } \\
\hline \begin{tabular}{|l} 
Linear programming** \\
\end{tabular} & & & & & & & & & & & & & & & & & \\
\hline
\end{tabular}


blocks. Number of blocks would vary across tribes depending on the area of habitation of the tribe in respective district. Household information will be elicited from any adult member of the household. The dietary recall and anthropometric measures would be taken on one eligible woman in the reproductive age group and an infant or child (between 6 months to 5 years) in each eligible household. In addition to this, biochemical assessment using finger prick blood samples will be done on the selected woman.

\section{Aim 1. Characterizing the food environment}

Aim 1 of the study involves characterizing the food environment, including the cultivated, wild and the market environments that the indigenous populations included in the study interface with. As part of this aim, we will address the following objectives: 1) appreciate knowledge and perception of specific tribal communities regarding their use of indigenous foods 2) map the biodiversity and assess availability, access and utilization of indigenous foods; 3 ) assess any shift in dietary patterns vis-à-vis indigenous food intake; 4) characterize farming systems to understand constraints and opportunities for improving indigenous food production and the resilience of these systems to climate variability; and 5) examine barriers and facilitators to increase sustainable production, procurement and consumption of indigenous foods. Table 2 provides an overview of the specific methodological approach that will be used to address each of the sub-objectives under aim 1 and their anticipated outcomes.

We will use tools developed by the Centre of Indigenous Peoples' Environment and Nutrition [28] as well as a toolkit developed by Bioversity International and the Institute of Development Studies on climate change and food security vulnerability [29] to guide our methodological approach for characterizing the food environment. We will use a combination of a village transect, semi-structured interviews (including free listing) and focus group discussions to: assess knowledge and perception of tribal communities regarding indigenous foods, map biodiversity, identify commonly consumed indigenous foods, assess shifts in dietary pattern, examine resilience of the present farming systems to climate variability and barriers and facilitators to sustainable production and consumption of indigenous foods. These qualitative methods will be complemented with quantitative methods that include an agricultural diversity tool for assessing crop species richness [24] (e.g., Shannon diversity, Modified Functional Attribute Diversity (MFAD) and population share with adequate nutrients) and a market survey that will provide insight into the price and availability of foods in the market food environments that the tribal communities have access to, so that we can examine the affordability and diversity of foods in the markets and identify gaps in food market access. The market survey has been adapted from a tool previously used to examine markets in Myanmar [30].

\section{Data analysis}

FGDs and interviews will be digitally recorded and transcribed verbatim. The FGD and interview transcripts will be coded in Atlas ti using grounded theory, based on the emergence of themes. We will use open, axial and selective coding to organize our data by key themes relating to the production and consumption of indigenous foods as well as the broader food system. The data analysis will be iterative and will continue to the point of theoretical saturation.

For assessing agricultural biodiversity, three separate measures namely crop species richness, crop varietal richness and crop nutritional functional richness will be calculated. [31, 32]

\section{Aim 2. Assessing the nutritive value of indigenous foods}

In order to assess the nutritive value of commonly consumed indigenous foods, standard protocols will be used to prepare herbariums of collected plant foods [33], followed by taxonomic classification by a botanist. After the identification, existing food composition tables will be searched to identify pre-existing information on the nutritive value of these foods, otherwise the item will be sent for nutrient analysis. Required quantities of the food sample for analysis will be collected from field sites, and transported in ice-coolers to the laboratory. The nutrient analysis will be carried out by a NABL (National Accreditation Board for Testing and Calibration Laboratories) accredited laboratory after verification of methods and quality check procedures. The sample collection and nutrient analysis will be done according to standard reference protocols developed as part of the study in consultation with the laboratory. The gravimetric method will be used for energy and fat, titrimetric for protein while carbohydrate will be measured by difference. The vitamins will be assessed using High Performance liquid Chromatography (HPLC) and the minerals by Inductively Coupled Plasma Mass Spectrometry (ICP-MS). The analyte values will be reported per $100 \mathrm{~g}$ of edible weight. The quality control procedures will be assessed, supervised and documented by the core research team throughout the analytical process. [34]

\section{Aim 3. Estimating the contribution of indigenous foods to nutrient intake and nutritional status}

The contribution of indigenous foods to the nutrient intake of the communities in our study, will be estimated through household surveys including dietary intake surveys and assessments of nutritional status, described in detail below. 


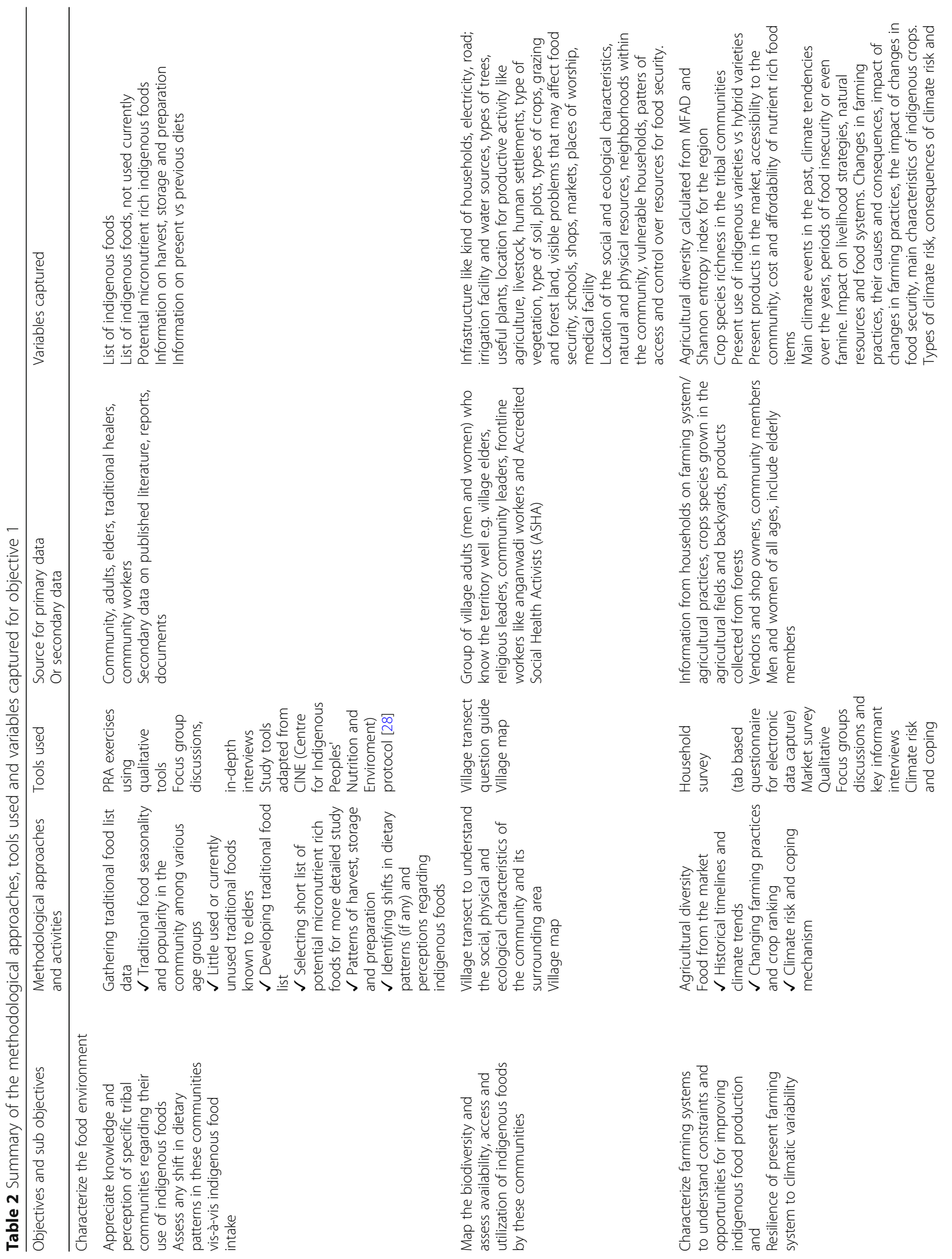




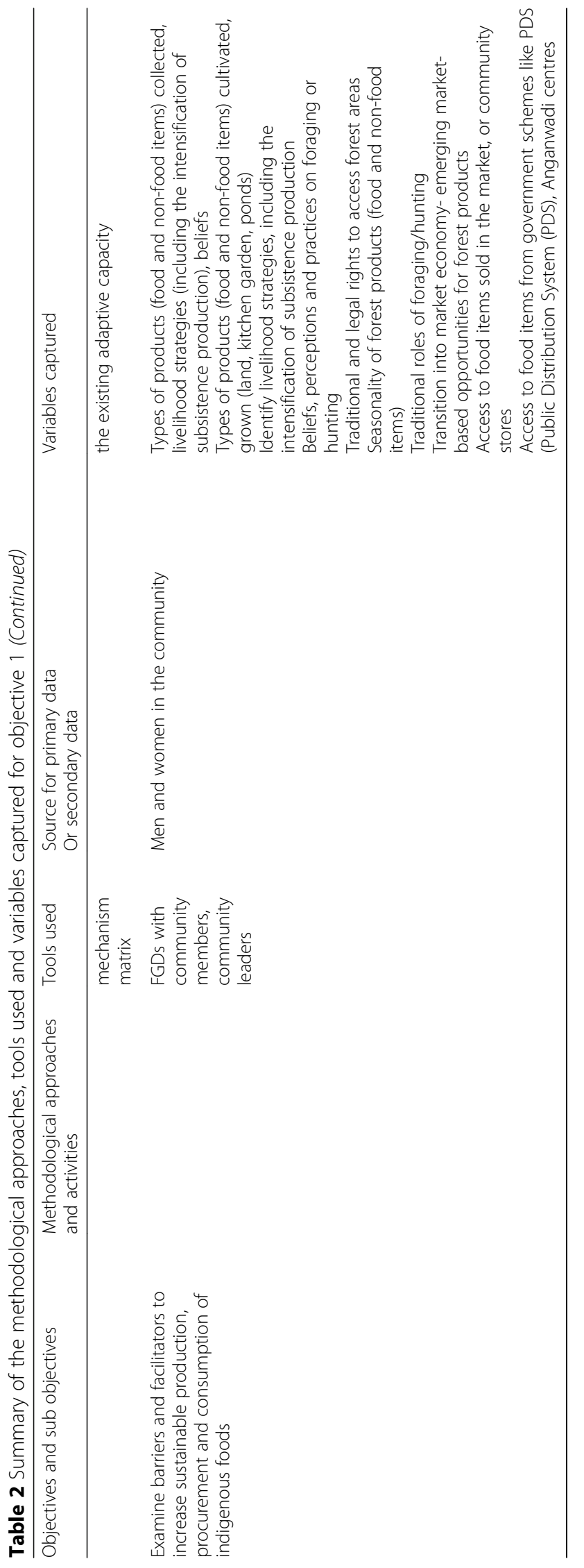


Sampling strategy All eligible households will be selected from the sampled villages (as explained in the overall sample section). A list of eligible women and children (6-23 months and 24-54 months) in each household will be prepared. We plan to have two strata of sample households. The first stratum will include children in the age range of 6-23 months and the second stratum will have children 24 to 59 months. In a household with a child from both the strata, the child in the first stratum will be selected. If there is more than one child in the same stratum, a Kish table will be used to select which child will be included in the study sample. One eligible woman from the selected household will then be randomly selected using a Kish table [35]. Note that the selected woman and the selected child's mother may be two different respondents in a specific household. We will assess dietary intakes and anthropometric measurements in the selected women and children, as described below.

Sample size We based our sample size calculation for each tribal population on the difference in mean dietary intake of iron ( $\mathrm{mg} /$ day) in women who consumed indigenous food as compared to women who did not consume indigenous food. Our sample size calculation suggests that we need at least 134 women per group in each of the tribal communities (leading to a total of 268 households per tribal group) to detect a difference of at least $30 \%$ in iron intake $(>3.4 \mathrm{mg}$ difference in absolute terms) between the two groups with $80 \%$ statistical power based on a two-sided test having $5 \%$ level of significance, after accounting for the loss in precision due to cluster sampling (assuming a design effect of 2). To calculate our sample size, we used estimates of mean iron $(11.3 \pm 7 \mathrm{mg} /$ day $)$ in the Santhal tribes based on previously published work [36]. In order to ensure that we have a large enough sample size, we plan to include 280 households per tribal group $(280 \times 4$ tribal groups $=$ 1120 households).

Households surveys An interviewer administered questionnaire will be used for the household surveys. Information will be collected on socio-economic and demographic characteristics, dietary intakes of women and children using a $24 \mathrm{~h}$ dietary recall and food frequency questionnaire (FFQ), traditional food patterns, seasonal dietary habits, procurement of food, food expenditure, infant and young child feeding practices of the index child and household food security. Anthropometric and biochemical assessments will be done in women and children. Data will be collected in real time on a tablet using CSPRo software (version 7) with inbuilt range checks.
Food security and dietary intake data Household food security will be assessed using the Food Insecurity Experience Scale which consists of eight questions related to the quantity and quality of foods that households have access to (FAO) [37]. The frequency of consumption of foods at the household level including indigenous foods will be assessed using a Food Frequency Questionnaire (FFQ). The FFQ will be based on a list of indigenous food items compiled from foods identified during qualitative enquires (i.e., free listing) conducted in specific tribal groups.

In addition to the FFQ, $24 \mathrm{~h}$ dietary recalls will be taken on two non-consecutive days for each selected woman and child per household. The woman respondent will be asked by an interviewer to recall, in as much detail as possible, her own food intake or the intake of her child during the past $24 \mathrm{~h}$ using a food recall kit which includes measuring cups, spoons and a portion size flip book. The respondent will be asked to recall, and wherever possible show or describe the foods eaten in each meal (i.e. each food item consumed along with a detailed recall of ingredients used, method of preparation, etc.). The recall will be repeated in another season on one third of the study participants to account for variability in seasonal nutrient intake. A digital pen technology will be used for documenting dietary recalls and FFQs. The data collection will happen in real time and the data entered in the $24 \mathrm{~h}$ dietary recall sheets will be directly entered into a database that will be linked to the data from Indian food composition table [38] and other primary and secondary nutrient databases. The $24 \mathrm{~h}$ dietary recalls will also be used to assess the Minimum Dietary Diversity - Women (MDD-W) indicator, [39] Minimum Dietary Diversity, minimum meal frequency and minimum acceptable diet indicators will be used to assess dietary diversity in children.

Anthropometric assessments Anthropometric assessments will be carried out on the same women and children for whom the dietary recall has been documented. Anthropometric measurements such as weight, height will be taken using standard protocols [40] and equipment. In children, Mid-upper Arm Circumference (MUAC) will also be measured. Body mass index (BMI) will be calculated as weight $(\mathrm{kg}) /$ height (in meters ${ }^{2}$ ) for women. The women will be classified as underweight or otherwise, using the BMI cut-offs [41]. The anthropometric assessment data from children will be entered in World Health Organization (WHO) "Anthro" software (version 3.2.2, 2011). Percent distribution of children according to weight for age, height/length for age, weight for height/length, as per WHO classification [42] will be conducted in order to assess prevalence of stunting, wasting and underweight. 
Biochemical assessment Five analytes (micronutrient and inflammatory biomarkers) will be concurrently estimated in capillary blood samples from 280 female subjects of reproductive age, from two tribal groups. These will be the same women on whom $24 \mathrm{~h}$ DR and anthropometric assessments will be done. The analytes include $\alpha$ - acid glycoprotein (AGP), C-Reactive Protein (CRP), ferritin, Retinol Binding Protein (RBP) and soluble Transferrin Receptor (sTfR). Samples will be collected from the selected woman in each household, by a certified, experienced laboratory personnel based on previously framed standard operating procedures. The samples will be stored after centrifugation and serum separation, in cryovials in a freezer at the field site and transported to the laboratory after collection is complete in one tribal group. The estimation of the biomarkers will be done using the Luminex assay ${ }^{\text {tox }}$ with drop array technology. Assay characteristics for all analytes, such as the Limit of Detection, Limit of Quantitation, dynamic range and linearity across concentrations will be defined and validated prior to estimating the biomarkers in the participants' serum. The biomarker concentrations will be adjusted for inflammation using the CRP and AGP before reporting the final values.

All the study tools will be translated by a native speaker into the local language and back-translated into English to check for fidelity, accuracy, and consistency. All data on HH survey, dietary intake, anthropometric measurements will be collected by field investigators and nutritionist after providing due trainings. The field investigators will be selected from the local communities, who are well versed with the local language. Core team members will always accompany the data collection team and will do periodic checks on the collected data.

Data analysis Nutrient intake data will be compared with Recommended Dietary Allowances (RDA) for Indians [43] for a moderately active adult female and for children under five and with WHO recommendations for complementary feeding for breast fed and non-breast fed children [44]. The adequacy of nutrient intake will be computed as Nutrient Adequacy Ratios (NAR) [45]. The NAR is equivalent to an individual's nutrient intake of a day divided by the RDA for the respective nutrient. The cut offs for the NAR are: inadequate $(<0.66)$, fairly adequate $(0.66-<1.00)$ and adequate $(\geq 1.00)$.

Continuous variables will be summarized as mean \pm standard deviation (SD) or as median and interquartile range (IQR), while categorical variables as number of subjects and percentages.

Women and children will be categorized into groups consuming and not consuming indigenous food based on the $24 \mathrm{~h}$ dietary recall. The nutrient intake, nutritional status and biomarkers in the two groups will be then compared. The t-test or Wilcoxon Rank sum test and chi-square test will be used to compare the differences in distribution of continuous and categorical variables, respectively. Two-sided tests will be used with statistical significance set at $P<0.05$. Analyses will be performed using STATA 13 (StataCorp, College Station, USA).

\section{Aim 4. Informing the development of interventions to support indigenous food consumption}

Value chain analysis and linear programming We will conduct a combination of value chain analysis and linear programming to help identify potential interventions aimed at supporting indigenous food consumption. More specifically, value chain analysis of the indigenous foods that have the greatest potential to address the nutrient gaps identified in Aim 3 will be conducted. The ways in which the selected indigenous foods move through the value chain from field-to-fork will be mapped with the view to identifying the bottlenecks in the value chain, and potential interventions that could improve their availability, affordability and acceptability. The value chain analysis will use a combination of semi-structured interviews $(\mathrm{n}=$ $\sim 30$ ) with purposively selected value chain actors and market analyses. The interviews will include topics related to the production of indigenous foods (including use of inputs and yields) as well as their processing, storage, retail (including profitability) and preparation. We will triangulate these data with data from the focus group discussions examining the barriers and facilitators to indigenous food consumption from Aim 1.

Additionally, we will use the linear programming software "Optifood" to inform the development of food-based recommendations based on the nutrients that tribal communities can obtain from their local food environments. Optifood analyzes the dietary patterns of target groups, and the costs of local foods, to identify the lowest cost diet that will meet the nutrient needs of the target group. We will use a combination of the dietary data from Aim 3 and the market data from Aim 2 as the basis for the Optifood analysis. [46].

\section{Discussion}

This study will provide the first comprehensive examination of the food system of tribal communities in Jharkhand state. Our exhaustive examination of the different components of the food system, and the way in which communities' interface with them, will facilitate development of context-specific interventions that are tailored to the needs of the population. Through our findings, we will identify interventions to help support the sustainable production and consumption of indigenous foods targeted at specific stakeholder groups. These interventions would ideally be incorporated into existing 
strategies and programs and help achieve the ultimate goal of the project which is to address food security, undernutrition and better nutrient intake in women and children as well as facilitate ecosystem conservation and biodiversity preservation.

In addition to informing the development of interventions to address the burden of malnutrition in the tribal communities in Jharkhand, the study will also build a methodological foundation for the development of future studies that aim to conduct a comprehensive assessment of the food systems of local communities. There is a dearth of empirical research examining local food systems and little is known about the best approaches to measuring them. This research will help contribute to the existing evidence base of measuring food systems in LMIC contexts.

A prototype for a multi-level approach including development of an evidence-based, context specific package of nutrition-sensitive interventions for encouraging production and consumption of these indigenous foods will be the primary outcome of the study. The prototype intends to inform how to incentivize production and consumption of indigenous foods throughout the food system as a whole. Finally, the robust scientific content would help in creating a conducive atmosphere for acceptance of indigenous foods as a bona fide and sustainable nutritional enhancement strategy in this part of the world.

\footnotetext{
Abbreviations

AGP: a- acid glycoprotein; AKS: Agroforestry Systems; BMI: Body Mass Index; CRP: C-Reactive Protein; FFQ: Food Frequency Questionnaire; FGD: Focus Group Discussions; HLPE: High Level Panel of Experts; HPLC: High Performance liquid Chromatography; ICP-MS: Inductively Coupled Plasma Mass Spectrometry; LMIC: Low and Middle Income Countries; MDDW: Minimum Dietary Diversity - Women; MFAD: Modified Functional Attribute Diversity; MUAC: Mid-upper Arm Circumference; NABL: National Accreditation Board for Testing and Calibration Laboratories; NAR: Nutrient Adequacy Ratios; PPS: Probability Proportional to Size; RBP: Retinol Binding Protein; RDA: Recommneded Dietary Allowances; sTfR: soluble Transferrin Receptor; TEK: Traditional Ecological Knowledge
}

\section{Acknowledgements}

The authors would like to acknowledge the invaluable contribution of staff at "Ekjut," a local NGO in Jharkhand. We would specifically like to acknowledge the support of Mr. Mohd, Sarfraz Ali during the protocol development work. The authors would also like to thank Mr. Manoj Soni for development of android based data collection platform for the study. We are very grateful to Dr. P Venkateswara Prasanna and Mr. Vinay Ranjan, scientists at the Central National Herbarium, Botanical Survey of India, Kolkata for their guidance for herbarium preparation protocol and facilitating the training of the field staff and Mr. Shyam Biswa and Mr. Alok Mukherjee for providing training for herbarium preparation. We would also like to thank Dr.Ravi Shankar at the Krishi Vigyan Kendra, Godda, for his inputs on local habitat and plant species. We thank Doxper Limited for their technical support in developing the tool for dietary data collection. The guidance from Dr.Andrew Jones and Dr. Danny Hunter through sharing of their knowledge and expertise in food systems, sustainable agriculture and assessing role of climate change on agriculture is greatly appreciated.
\end{abstract}

\section{Funding}

This work was supported by the Wellcome Trust/DBT India Alliance Fellowship (https://www.indiaalliance.org/) [IA/CPHI/16/1/502639] awarded to Suparna Ghosh-Jerath. The study proposal was reviewed and approved by the funding agency. However, the funding agency has no role to play in the final design of the study, data collection, analysis, and interpretation of data and in writing the manuscript.

\section{Availability of data and materials}

Not applicable.

\section{Authors' contributions}

SGJ, AS and SD conceived the study with overall supervision from JF and GG. SGJ, AS, SD and SP developed the study design and tools for data collection and analysis plan. SGJ AS and SD prepared the first draft of the manuscript. All authors contributed to critique and modification of the manuscript, read and approved the final version. SGJ had final responsibility for the decision to submit for publication.

\section{Ethics approval and consent to participate}

The study protocol along with the study tools has been approved by the Institutional Ethics Committee (IEC) at Indian Institute of Public HealthDelhi, Public Health Foundation of India and All India Institute of Medical Sciences, New Delhi. The study is conducted by IIPH-Delhi team in rural Jharkhand and the approval is valid for the study site. Written consents at the cluster level as well as at individual level would be taken by the field investigators. In case the study participant is illiterate, verbal witnessed consent would be taken. The minimum age of adult member who would respond to the household survey will be 18 years. However, in the reproductive age group women on whom we would administer $24 \mathrm{~h}$ dietary recalls, take anthropometric measurements and do biochemical assessments, we may expect the women between the age of $15-49$ years. In case, a woman is 18 years or above in this group, we will take consent. In case, the age of the woman in the reproductive age group is less than 18, we will take assent from the participant and consent from the parent or guardian. For children ( 6 months to 5 years) consent from parent or guardian will be taken. All the consent taking modalities and consent forms have been approved by the IECs. Name, address, age of the family members in the study households will be collected for record purposes. Household and its members will be given a unique study identification code. All the identifiable information will be delinked from the database at the time of analysis and dissemination of results.

The core team will have access and link for identifying the unique study identification code to identify the participants. All data will be saved in password protected computers. The blood report and anthropometric assessments will be shared with respective study participants.

\section{Consent for publication}

Not applicable.

\section{Competing interests}

The authors declare that they have no competing interests.

\section{Publisher's Note}

Springer Nature remains neutral with regard to jurisdictional claims in published maps and institutional affiliations.

\footnotetext{
Author details

${ }^{1}$ Indian Institute of Public Health-Delhi, Public Health Foundation of India, Plot no 47, Sector 44, Institutional Area, Gurgaon 122002, India. ${ }^{2}$ Department of Health Systems and Policy, Rutgers School of Public Health, Rm. 426, 112 Paterson, St. New Brunswick, NJ 08901, Canada. ${ }^{3}$ All India Institute of Medical Sciences, Ansari Nagar, New Delhi 110029, India. ${ }^{4}$ National Council of Applied Economic Research (NCAER), Parisita Bhawan, 11 Indraprastha Estate, New Delhi 110002, India. ${ }^{5}$ Nutrition and Bone Health Research Group, MRC Human Nutrition Research, Elsie Widdowson Laboratory, Fulbourn Road, Cambridge CB1 9NL, UK. 'Department of International Health, Johns Hopkins Bloomberg School of Public, Health Berman Institute of Bioethics, Johns Hopkins Nitze School of Advanced International Studies, 1809 Ashland Avenue, Baltimore, MD 21205, USA.
} 
Received: 4 February 2019 Accepted: 13 May 2019 Published online: 15 July 2019

\section{References}

1. Wang ZG, Jin X, Bao XG, Li XF, Zhao JH, Sun JH, Christie P, Li L. Intercropping enhances productivity and maintains the most soil fertility properties relative to sole cropping. PloS one. 2014 Dec 8;9(12):e113984 Available from : doi:https://doi.org/10.1371/journal.pone.0113984.

2. Behera RN, Nayak DK, Andersen P, Måren IE. From jhum to broom: agricultural land-use change and food security implications on the Meghalaya plateau, India. Ambio. 2016 Feb 1;45(1):63-77. Available from. https://doi.org/10.1007/s13280-015-0691-3.

3. Jones AD. On-Farm Crop Species Richness Is Associated with Household Diet Diversity and Quality in Subsistence-and Market-Oriented Farming Households in Malawi-3. The Journal of nutrition. 2017 Jan;147(1):86-96. Available from doi: https://doi.org/10.3945/jn.116.235879.

4. Food and Agriculture Organization of the United Nations (ROME). The state of food security and nutrition in the world : building climate resilience for food security and nutrition . 2018; Available http://www.fao.org/3/19553EN/ i9553en.pdf.

5. Tzioumis E, Adair LS. Childhood dual burden of under-and overnutrition in low-and middle-income countries: a critical review. Food and nutrition bulletin. Jun. 2014;35(2):230-43. Available from. https://doi.org/10.1177/ 156482651403500210

6. Haddad L, Cameron L, Barnett I. The double burden of malnutrition in SE Asia and the Pacific: priorities, policies and politics. Health policy and planning. 2014 Oct 15;30(9):1193-206. Available from: doi: https://doi.org/10 1093/heapol/czu110

7. Burlingame B, Dernini S. Sustainable Diets and Biodiversity: Directions and Solutions for Policy, Research and Action. International Scientific Symposium, Biodiversity and Sustainable Diets United Against Hunger, FAO Headquarters, Rome, Italy, 3-5 November 2010. In Sustainable Diets and Biodiversity: Directions and Solutions for Policy, Research and Action. International Scientific Symposium, Biodiversity and Sustainable Diets United Against Hunger, FAO Headquarters, Rome, Italy, 3-5 November 2010. 2012. Food and Agriculture Organization of the United Nations (FAO). Available from: http://www.fao.org/ag/humannutrition/29186021e012ff2db1 b0eb6f6228e1d98c806a.pdf

8. Galluzzi G, Van Duijvendijk C, Collette L, Azzu N, Hodgkin T. Biodiversity for food and agriculture. Contributing to food security and sustainability in a changing world. PAR platform, FAO, Rome. 2011. Available from: http:// www.fao.org/fileadmin/templates/biodiversity_paia/PAR-FAO-book_Ir.pdf.

9. Bhattacharjee LA, Kothari GO, Priya VI, Nandi BK. The Bhil food system: links to food security, nutrition and health. FAO of the UN: Rome, Italy; 2009. Available from: http://www.fao.org/tempref/docrep/fao/012/i0370e/ i0370e11.pdf

10. Kuhnlein HV, Erasmus B, Spigelski D. Indigenous peoples' food systems: the many dimensions of culture, diversity and environment for nutrition and health. Rome, Italy: Food and Agriculture Organization of the United Nations; 2009 Jun

11. Swepston L. A new step in the international law on indigenous and tribal peoples: ILO convention no. 169 of 1989. Okla City UL Rev. 1990;15:677. Available from: https://www.ilo.org/global/topics/indigenous-tribal/WCMS_ 503321/lang\%2D\%2Den/index.htm.

12. Rook JM. The SADC regional early warning system: experience gained and lessons learnt from the 1991-92 southern Africa drought. Using Science Against Famine: Food Security, Famine Early Warning. 2005:163.

13. Nethononda LO, Odhiambo JO, Paterson DG. Indigenous knowledge of climatic conditions for sustainable crop production under resource-poor farming conditions using participatory techniques. Sustainable Agriculture Research. 2012 Sep 20;2(1):26.

14. Rankoana SA. Perceptions of climate change and the potential for adaptation in a rural community in Limpopo Province, South Africa. Sustainability. 2016 Aug 4;8(8):672.

15. Reid H, Huq S. Mainstreaming community-based adaptation into national and local planning. Clim Dev. 2014;6:291-2.

16. Leakey RR. The role of trees in agroecology and sustainable agriculture in the tropics. Annu Rev Phytopathol. 2014 Aug 4;52:113-33.

17. Marie CN, Sibelet N, Dulcire M, Rafalimaro M, Danthu P, Carrière SM. Taking into account local practices and indigenous knowledge in an emergency conservation context in Madagascar. Biodivers Conserv. 2009 Sep 1;18(10): 2759-77. Available at. https://doi.org/10.1007/s10531-009-9672-9.

18. Chivenge P, Mabhaudhi T, Modi AT, Mafongoya P. The potential role of neglected and underutilised crop species as future crops under water scarce conditions in sub-Saharan Africa. Int J Environ Res Public Health. 2015 May 26;12(6):5685-711. https://doi.org/10.3390/ijerph120605685.

19. Ramakrishnan PS. Increasing population and declining biological resources in the context of global change and globalization. J Biosci. 2001 Nov 1: 26(4):465-79.

20. Vallejo-Ramos M, Moreno-Calles Al, Casas A. TEK and biodiversity management in agroforestry systems of different socio-ecological contexts of the Tehuacan Valley. J Ethnobiol Ethnomed. 2016 Dec;12(1):31. https:// doi.org/10.1186/s13002-016-0102-2.

21. Das MB, Mehta SK. Poverty and social exclusion in India: Adivasis. World Bank. Retrieved from: http://siteresources.worldbank.org/ EXTSOCIALDEVELOPMENT/Resources/244362-1265299949041/67663281285599693282/India-PSE-Adivasis_Brief.pdf. 2010.

22. Kasimba SN, Motswagole BS, Covic NM, Claasen N. Household access to traditional and indigenous foods positively associated with food security and dietary diversity in Botswana. Public Health Nutr. 2018 Apr;21(6):1200-8. https://doi.org/10.1017/S136898001700369X.

23. M'Kaibi FK, Steyn NP, Ochola SA, Du Plessis L. The relationship between agricultural biodiversity, dietary diversity, household food security, and stunting of children in rural Kenya. Food science \& nutrition. 2017 Mar;5(2): 243-54. https://doi.org/10.1002/fsn3.387.

24. Jones AD, Hoey L, Blesh J, Miller L, Green A, Shapiro LF. A systematic review of the measurement of sustainable diets-3. Adv Nutr. 2016 Jul 11;7(4):64164 https://doi.org/10.3945/an.115.011015.

25. Food and Agriculture Organization of the United Nations (Rome). Nutrition and food systems. A report by the High Level Panel of Experts on Food Security and Nutrition of the Committee on World Food Security. HLPE Report 12. 2017 September. Available from: http://www.fao.org/3/a-i7846e. pdf.

26. Moreno-Calles Al, Casas A, Rivero-Romero AD, Romero-Bautista YA, RangelLanda S, Fisher-Ortíz RA, Alvarado-Ramos F, Vallejo-Ramos M, Santos-Fita D. Ethnoagroforestry: integration of biocultural diversity for food sovereignty in Mexico. J Ethnobiol Ethnomed. 2016 Dec;12(1):54. https://doi.org/10.1186/ s13002-016-0127-6.

27. Delhi RN. Office of the Registrar General and Census Commissioner of India; 2011. http://www.censusindia.gov.in/2011census/SCST-Series/ST14.html

28. Kuhnlein HV, Smitasiri S, Yesudas S, Bhattacharjee L, Dan L, Ahmed S. Documenting traditional food systems of indigenous peoples: international case studies. In: Centre for Indigenous Peoples' nutrition and environment: McGill University, Sainte-Anne-de-Bellevue, Quebec. Downloadable from: www. mcgill. ca/files/cine/manual. pdf. 2006 Apr.

29. Ulrichs M, Cannon T, Newsham A, Naess LO, Marshall M. Climate Change \& Food Security Vulnerability Assessment. Toolkit for assessing communitylevel potential for adaptation to climate change. 2015 June. https://cgspace. cgiar.org/handle/10568/66566.

30. Downs SM, Glass S, Linn KK, Fanzo J. The interface between consumers and their food environment in Myanmar: an exploratory mixed-methods study. Public health nutrition, vol. 18; 2018 Dec. p. 1-4.

31. Remans R, Flynn DF, DeClerck F, Diru W, Fanzo J, Gaynor K, Lambrecht I, Mudiope J, Mutuo PK, Nkhoma P, Siriri D. Assessing nutritional diversity of cropping systems in African villages. PLoS One. 2011 Jun 16;6(6):e21235.

32. Jones AD. On-farm crop species richness is associated with household diet diversity and quality in subsistence-and market-oriented farming households in Malawi-3. J Nutr. 2016 Oct 12;147(1):86-96 https://doi.org/10. 3945/jn.116.235879.

33. Santapau SJ. Instructions for field collectors of the Botanical Survey of India.

34. Nollet LM, Toldrá F. Food analysis by HPLC: CRC Press; 2012 Nov 16.

35. World Health Organization. The world health survey sampling guidelines for participating countries. Geneva: WHO; 2002.

36. Ghosh-Jerath S, Singh A, Magsumbol MS, Lyngdoh T, Kamboj P, Goldberg $\mathrm{G}$. Contribution of indigenous foods towards nutrient intakes and nutritional status of women in the Santhal tribal community of Jharkhand, India. Public Health Nutr. 2016 Aug;19(12):2256-67. https://doi.org/10.1017/ S1368980016000318

37. Gustafson DI , Gutman A, Leet W, Drewnowski A, Fanzo J.(2016) Seven food system metrics of sustainable nutrition security. Sustainability, $8, x ;$ doi:10. 3390/ ttp://www.fao.org/in-action/voices-of-the-hungry/fies/en/). 
38. Longvah T, Anantan I, Bhaskarachary K, Venkaiah K. Indian food composition tables: National Institute of Nutrition, Indian Council of Medical Research; 2017.

39. United States Agency for International Development. Minimum dietary diversity for women: food and nutrition technical assistance III project (FANTA).[cited on 2019 January 25]. Available from: https://www. fantaproject.org/monitoring-and-evaluation/minimum-dietary-diversitywomen-indicator-mddw.

40. Jelliffe DB. World Health Organization. The assessment of the nutritional status of the community (with special reference to field surveys in developing regions of the world); 1966

41. World Health Organization (EC). Appropriate body-mass index for Asian populations and its implications for policy and intervention strategies. Lancet (London, England). 2004 Jan 10;363(9403):157.

42. World Health Organization. WHO child growth standards: length/height for age, weight-for-age, weight-for-length, weight-for-height and body mass index-for-age, methods and development: World Health Organization; 2006. Available from: http://www.who.int/childgrowth/ standards/Technical_report.pdf

43. Indian Council of Medical Research (ICMR). Nutrient requirements and recommended dietary allowances for Indians. A report of the expert group of the Indian Council of Medical Research. Hyderabad, India: National Institute of Nutrition; 2010.

44. World Health Organization, World Health Organization. Complementary feeding of young children in developing countries: a review of current scientific knowledge. Geneva: Who; 1998. p. 230

45. Malhotra A, Passi SJ. Diet quality and nutritional status of rural adolescent girl beneficiaries of ICDS in North India. Asia Pac J Clin Nutr. 2007 Apr 1; 16(S1):8-16.

46. United States Agency for International Development. Optifood: Food and Nutrition Technical Assistance III Project (FANTA). [Cited 2018 January 25] Available from: https:/www.fantaproject.org/tools/optifood.

Ready to submit your research? Choose BMC and benefit from:

- fast, convenient online submission

- thorough peer review by experienced researchers in your field

- rapid publication on acceptance

- support for research data, including large and complex data types

- gold Open Access which fosters wider collaboration and increased citations

- maximum visibility for your research: over $100 \mathrm{M}$ website views per year

At $\mathrm{BMC}$, research is always in progress.

Learn more biomedcentral.com/submissions 